\title{
Ultrastructure of vascular and connective tissue changes in primary syphilis
}

\author{
TERESA WRZOLKOWA* AND JERZY KOZAKIEWICZ† \\ From the *Electron Microscopy Laboratory and †Dermatology Clinic, University of Gdansk Medical \\ School, Gdansk, Poland
}

SUMMARY Electron microscopical studies of primary syphilitic lesions showed intensive changes in the capillaries in the form of endothelial proliferation and extensive infiltration of different cells in the surrounding connective tissue. The degenerative changes in axon terminals could explain the painless course of primary induration.

\section{Introduction}

Until recently there have been few published reports on the ultrastructure of the syphilitic chancre, most of them dealing with the behaviour of spirochaetes in the early phases of infection..$^{1-5}$

The aim of this investigation was to define the character of the abnormalities in the capillaries of the skin and in the surrounding connective tissue in primary syphilitic foci.

\section{Patients and methods}

Skin specimens from seven patients treated in the dermatology clinic of the Medical Academy of Gdansk between 1974 and 1978 were examined. Three patients had sero-positive primary syphilis and four had sero-negative primary syphilis (negative results to lipoidal antigen tests, although the titre of the fluorescent treponemal antibody absorbed test varied from $1 / 450$ to $1 / 1300$ ). The primary changes localised on the prepuce or the glans penis had been present for 3-6 days before examination by electron microscopy in three cases and for 16-20 days in the remaining cases.

The specimens were immediately fixed with $6 \cdot 25 \%$ glutaraldehyde in $0.1 \mathrm{~mol} / \mathrm{l}$ cacodylate buffer (pH 7.4); postfixation was performed in a similarly buffered $2 \%$ solution of osmium tetroxide and embedded in Epon 812. Ultrathin sections were stained with lead citrate and uranyl acetate. They were viewed in a JEM 7A electron microscope.

Address for reprints: Dr T Wrzołkowa, Electron Microscopy Laboratory, Gdansk University Medical School, Debinki 1, 80-211 Gdansk, Poland

Received for publication 27 April 1979

\section{Results}

\section{ENDOTHELIAL PROLIFERATION}

Electron microscopical studies of the syphilitic chancres showed considerable changes in the capillaries, mainly in the form of endothelial proliferation obliterating the vascular lumen. The cytoplasm of most of these cells showed features of stimulation with numerous mitochondria, ribosomes, and contractile fibres present and a proliferation of rough and smooth endoplasmic reticulum. Some of the endothelial cells were only swollen and showed no signs of proliferation. The coexistence of both types of changed endothelial cells in a single capillary section was noticeable.

The basement membrane of the capillaries was often multilaminated and thickened segmentally (figs 1 and 2). No electron-dense deposits were observed.

Between the layers of the basement membrane homogeneous material of moderate electron-optical density, numerous undifferentiated fibres and fibrils, occasional fibrin threads, and deposits of proteoglycans were visible.

\section{CELLULAR INFILTRATION}

The proliferation of pericytes was as prominent as that of the endothelial cells. A characteristic feature of the primary syphilitic foci was an extensive infiltration of lymphocytes, plasma cells, histiocytes, and mast cells. In places some of the cells were closely packed, leaving only an occasionally visible intercellular space between the cell membranes (fig 3). Such an interaction of cells was seen between macrophages, lymphocytes, and plasma cells.

Intensive cellular infiltration was usually observed in specimens from older foci. In two cases, the cellular infiltration was scanty. In the perivascular space extensive agglomerations of a homogeneous or 


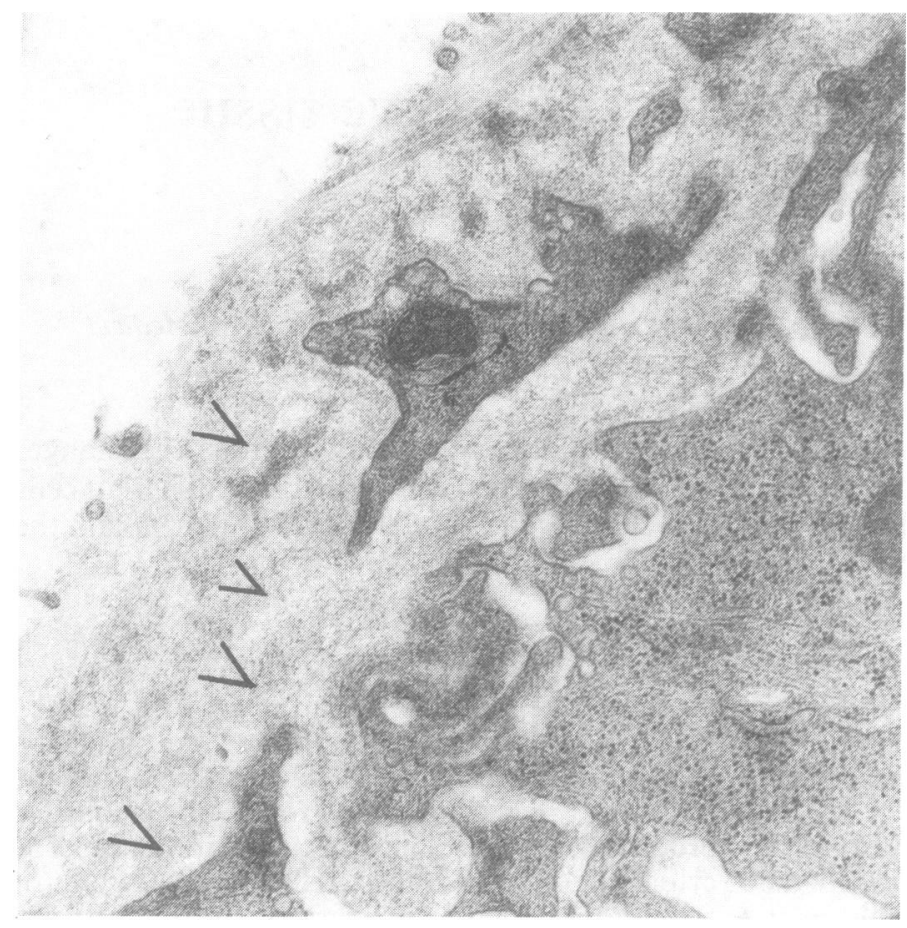

FIG 1 Fragment of capillary with stimulated endothelial cell and multilayered ()) basement membrane. $\times 27000$ magnification.

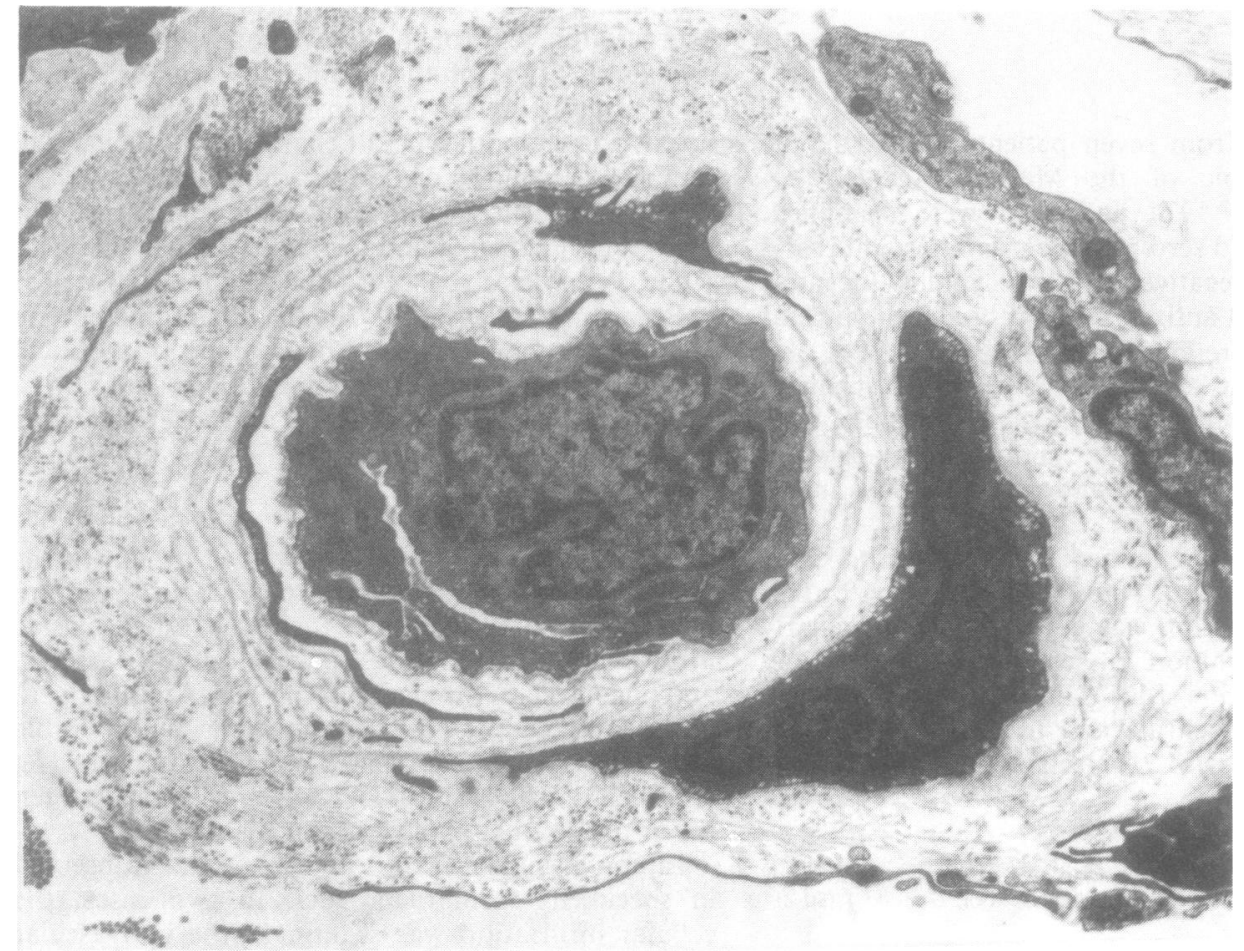

FIG 2 Capillary vessel with a thick multilayered basement membrane. $\times 7000$ magnification. 


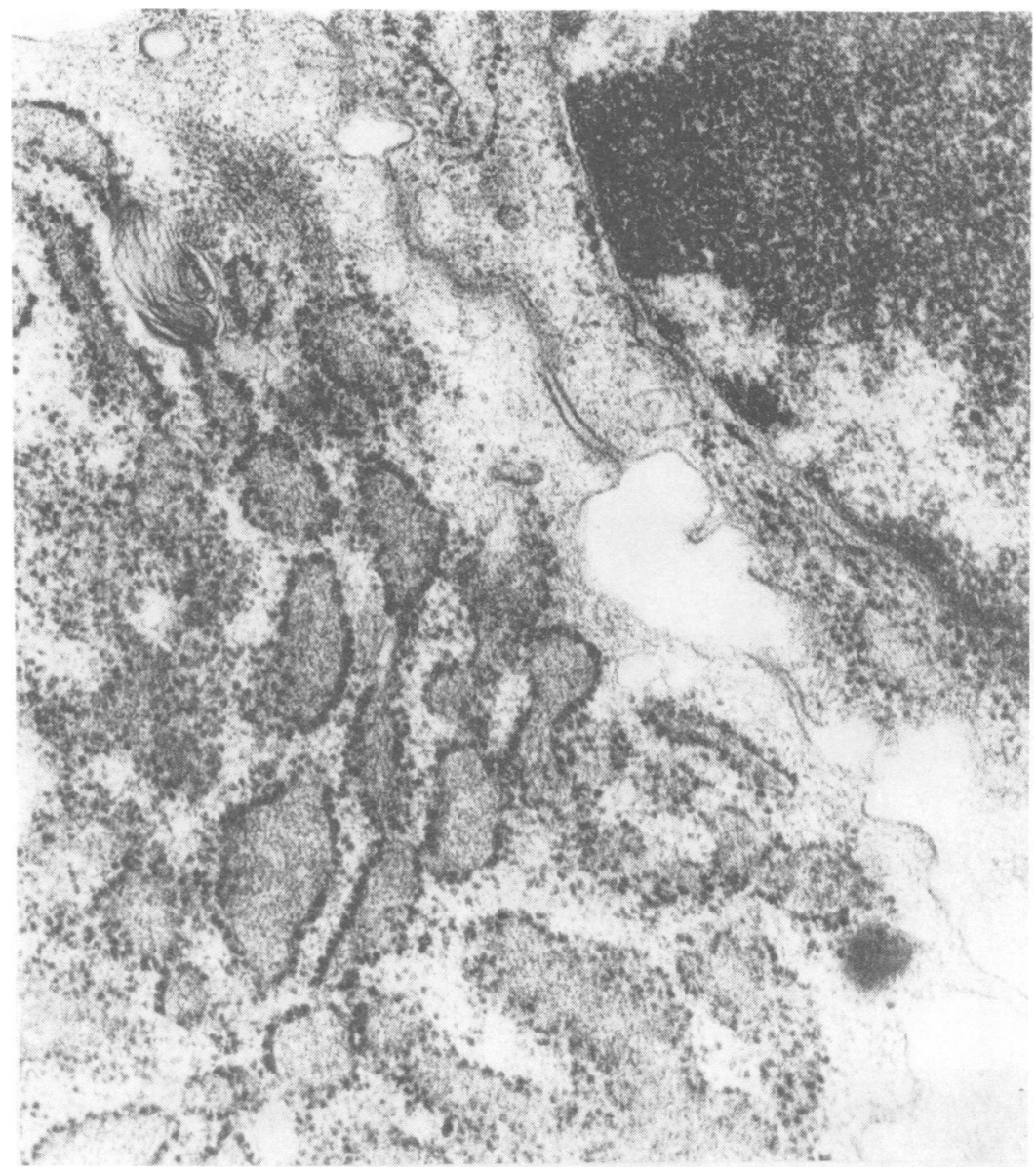

FIG 3 Closely opposed inflammatory cells with their cell membranes partially invisible. $\times 46000$ magnification.

finely granular material were visible. This material was of moderate electron-optical density with numerous thread-like deposits, probably of fibrin.

In most of the studied specimens undifferentiated fibrils and elastic and collagen fibres in different phases of development were present in the perivascular area, usually within the region of infiltration.

Some of the axon terminals showed signs of a degenerative process (fig 4).

\section{TREPONEMES}

Treponemes were present in all sections studied. They were most numerous in the capillary walls between the endothelial and pericytic cells.

In the region of infiltration and in the epidermis extracellular treponemes were visible near the cell membranes (fig 5). In areas of close approximation of the treponemes, the cell membrane was indented (fig 6).
Treponemes and fragments of their outer envelope (fig 7) were also present in the exudate outside the area of infiltration. Intracellular treponemes were rarely observed (figs 8 and 9). Fragments of their bodies were surrounded by cytoplasmic processes forming a kind of niche (fig 8). Sometimes they were found in the cytoplasm in vacuoles (fig 9). The intracellular organisms were always devoid of the external envelope, fragments of which were visible in the intercellular spaces (fig 7).

\section{Discussion}

The aim of this report was to explain the character of the lesions in the capillaries of the skin in primary syphilitic lesions. The response of the vessels was complex, some of the endothelial and pericytic cells showing proliferation, others being only swollen. Both types of reaction were visible in a single capillary. This could be explained by the variable 


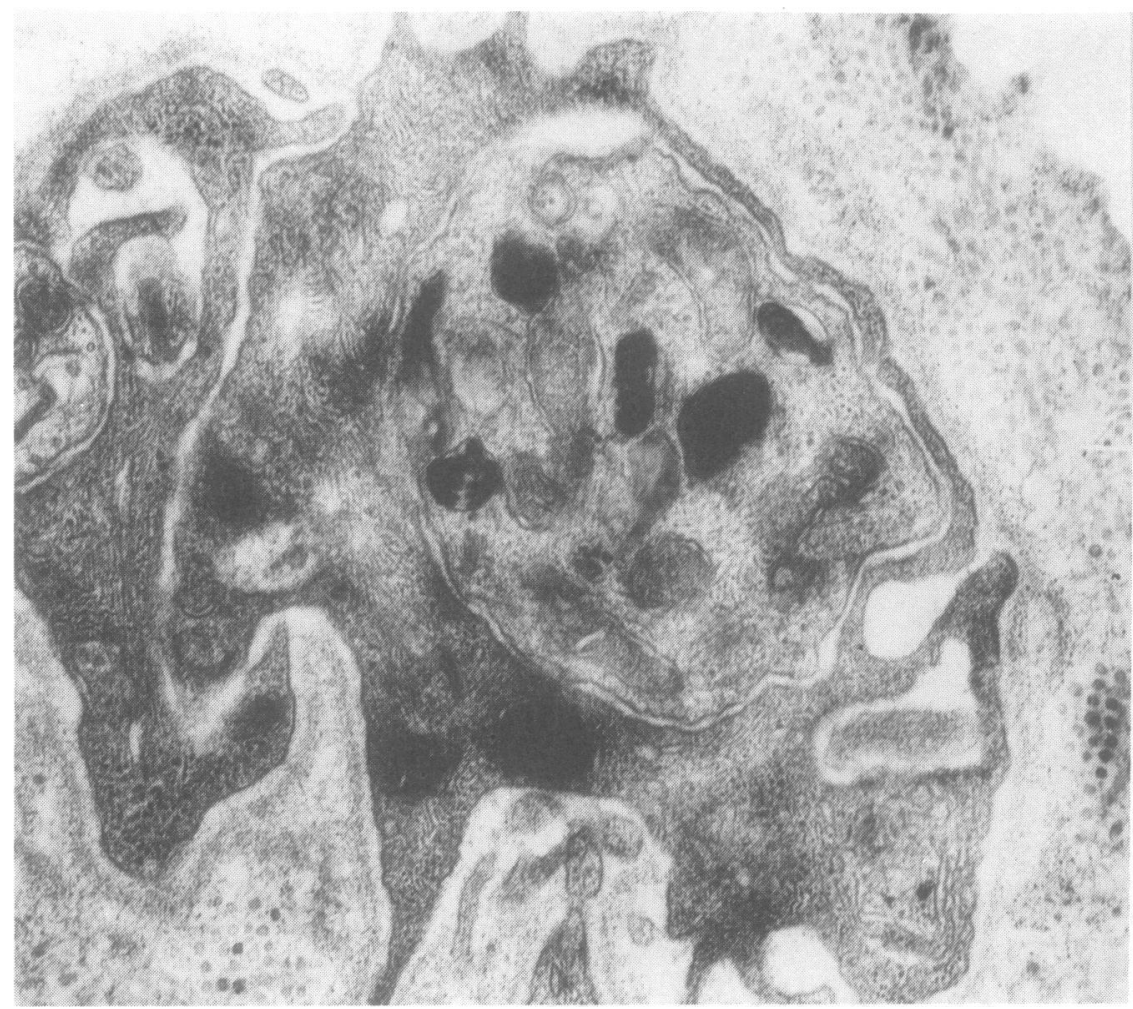

FIG 4 Fragment of degenerated axon terminal. $\times 36000$ magnification.

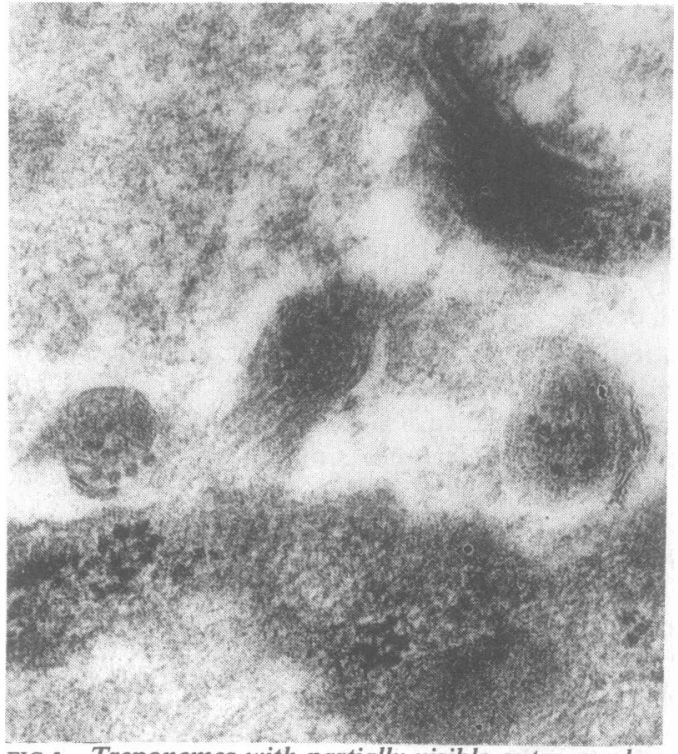

FIG 5 Treponemes with partially visible outer envelope among amorphous exudate and nearby inflammatory cells. $\times 65000$ magnification.

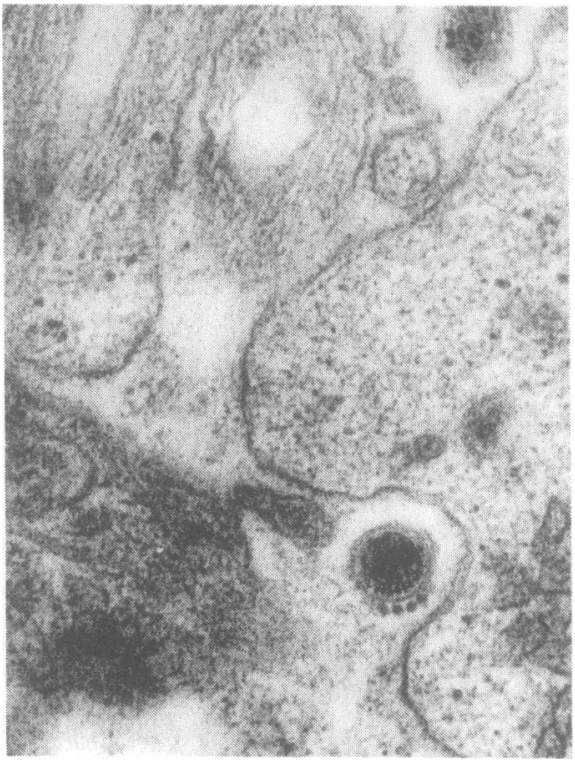

FIG 6 Treponemes intimately related to a cell in a niche formation. $\times 40000$ magnification. 


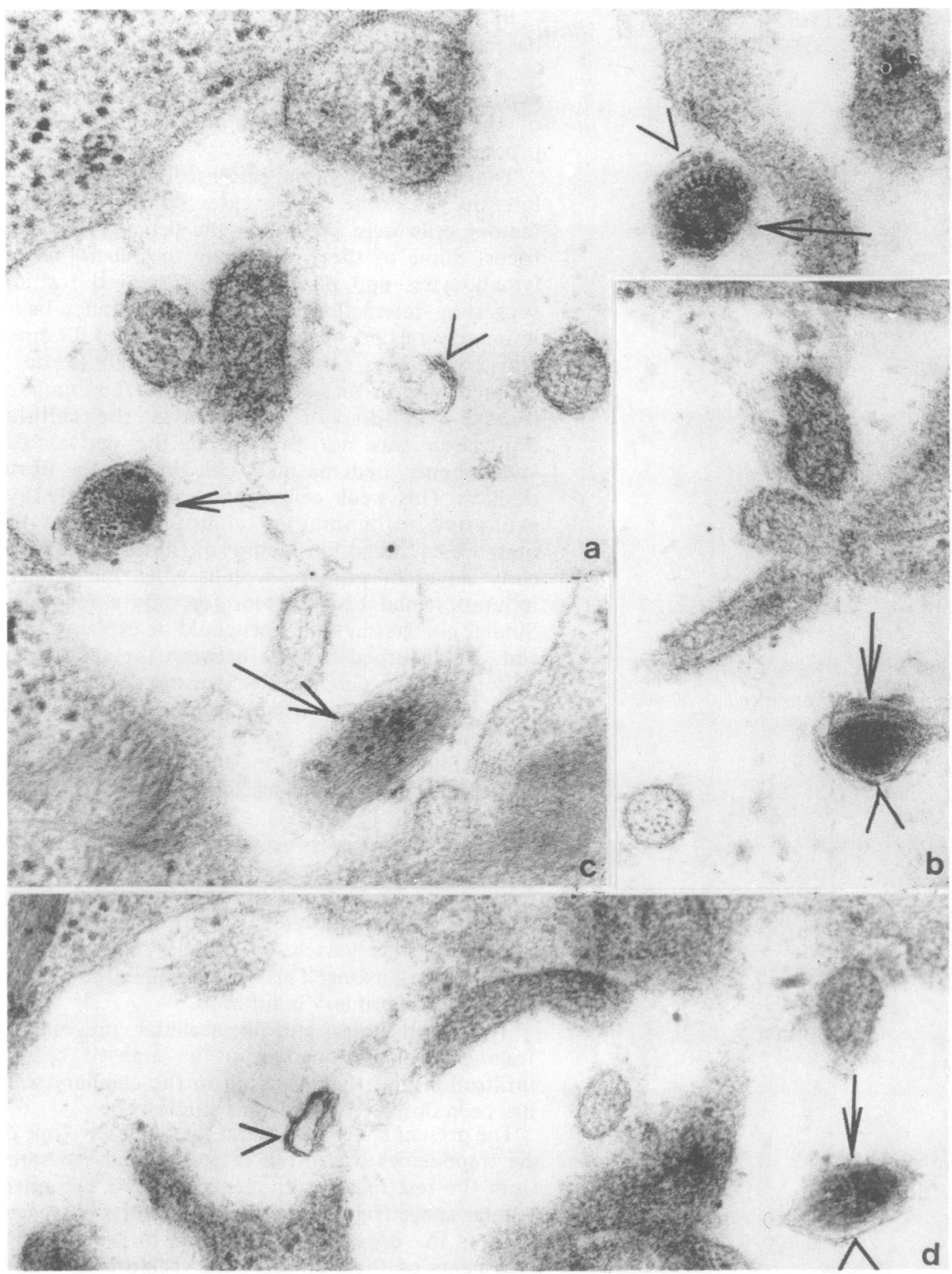

FIG 7 Treponemes in the extracellular space. (Arrows indicate treponemes.) Outer envelope $\gg$ ) attached or separated from treponeme. (a) $\times 75$ 000; (b) $\times 67$ 000; (c) $\times 75$ 000; and (d) $\times 60000$ magnification.

intensity of the toxic factor or the different functional state of the cells at the moment of injury. It is difficult to exclude other factors influencing the function of the cell.

The presence of treponemes inside the capillaries has been reported by a number of authors. ${ }^{34}$ The basement membrane of most of the capillaries in the sections was multilaminated. This type of basement membrane is characteristic of the venous capillary. Braverman and Yen $^{6}$ described similar basement membranes in the vessels of the papillary and subpapillary layers of the skin in psoriasis. 


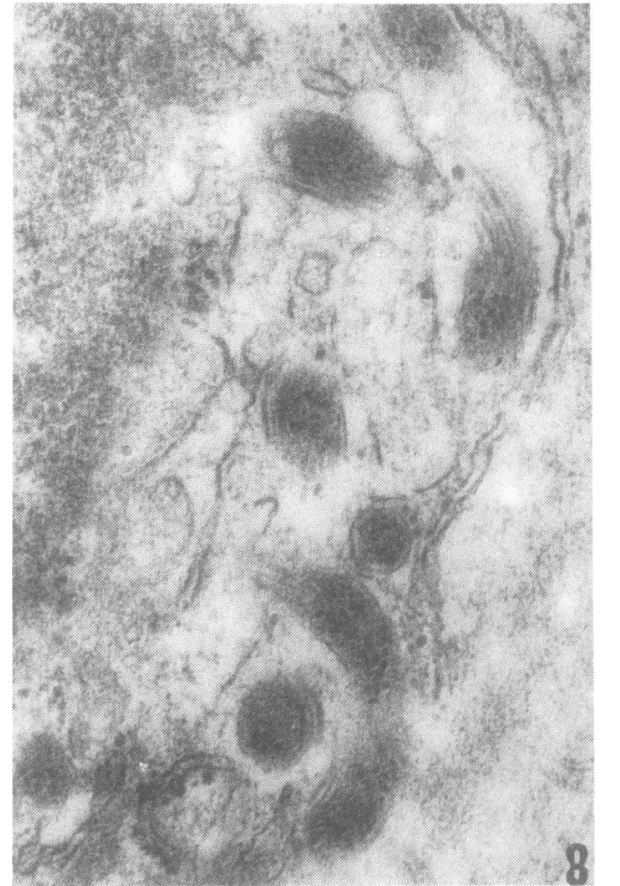

FIG 8 Treponemes penetrating into a cell. $\times 50000$ magnification.

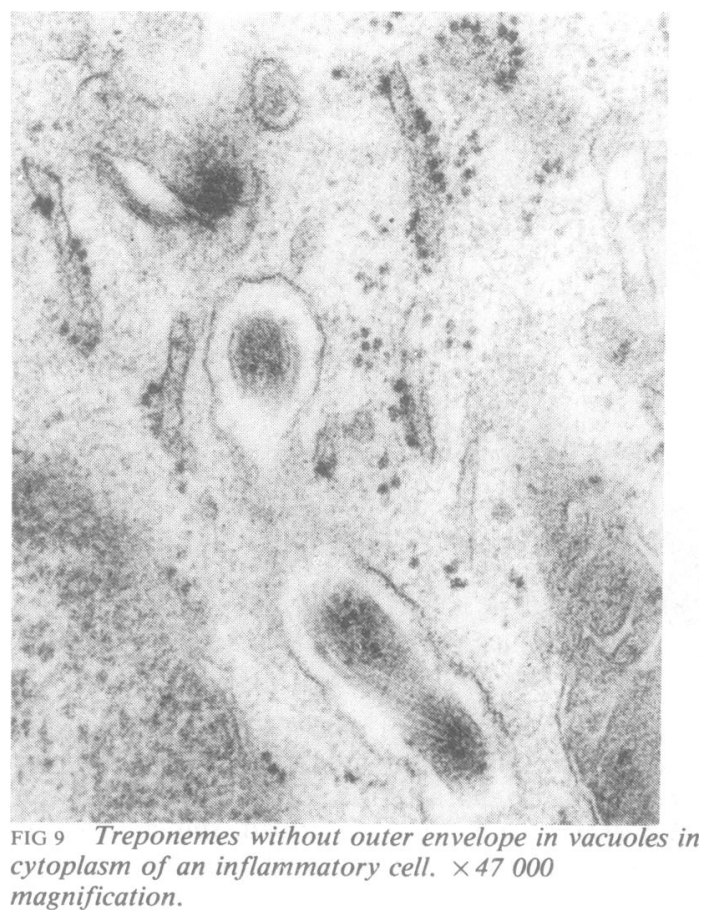

In the primary syphilitic focus such a changed basement membrane was visible in the infiltrated area of the dermal papillae and the subpapillary dermis. It is probable that this is a structural reaction of the basement membrane to the inflammatory process.

The cell reaction in the perivascular area varied in intensity. In some of the cases numerous inflammatory cells were present in the primary syphilitic focus. Some of these, especially the macrophages, lymphocytes, and plasma cells, displayed features suggesting interaction, their cell membranes being intimately related in places. According to Twomey and co-workers ${ }^{7}$ this phenomenon could be a characteristic of one of the phases of the immunological reaction. In other cases the cellular infiltration was not prominent, the perivascular space being oedematous with numerous fibrin threads. This weak cell response and an extensive exudative inflammatory component, with the presence of thread-like clumps of fibrin, appeared in early stages of primary syphilis when the primary induration had been present for only a few days. Similar changes in older foci could be explained as a state of disturbed balance between the aetiological factor and the defence mechanisms of the human organisms due to the variable number or virulence of the treponemes.

The intensive formation of filaments, collagen, and elastic fibres was characteristic of foci of longer duration.

The degenerative process in the terminal axons seen in our studies has been previously reported in studies on experimental syphilis in rabbits. ${ }^{8}$ This process was observed in axon terminals not associated with vessels or muscle cells, probably being sensory axons. This could explain the painless course of the primary induration.

The intercellular and intracellular presence of fragments of treponemes in the area of cellular infiltration and their location in the capillary walls has been observed in previous studies. ${ }^{2-4}$

The present study shows that the outer envelope of the treponemes was often destroyed and separated from the rest of the treponemal body in the intercellular space (fig 7). The outer envelope was never visible in organisms situated intracellularly. Fragments of their bodies were visible in oval and round vacuoles. It has been suggested that treponemes enter the cytoplasm by way of endocytosis. ${ }^{9}$ Phagocytosis observed in experimental syphilis seems to support this view. During this process macrophages were seen to surround the organisms with cytoplasmic processes, engulfing them within the cell in vacuoles. ${ }^{45}$

Brause and Roberts ${ }^{10}$ reported different findings. 
They observed in vivo that the spirochaetes concentrated around the macrophages, which showed no phagocytic reaction. At the same time the macrophages quickly absorbed molecules of latex used in the experiment. The authors believed that live mobile treponemes possess antiphagocytic surface factors which prevent their phagocytosis. If these factors were connected with the outer envelope of the organism, the destruction or separation of this envelope-as observed in our studies-could cause endocytosis of the treponemes by appropriate cells. As an effect of this process they become visible intracellularly in oval areas surrounded by an indentation of the cell membrane. In view of the studies carried out by Brause and Roberts, ${ }^{10}$ and of our own reports, it seems that the weakening of the biological properties of the treponemes and the damaging of their structure are essential for their phagocytosis by appropriate cells.

\section{References}

1. Azar H, Pham T, Kurban A. An electron microscopic study of a syphilitic chancre. Arch Pathol 1970;90: 143-50.

2. Hasagawa $\mathbf{T}$. Electron microscopic observations on the lesion of condyloma latum. Br J Dermatol 1969;81:367-74.

3. Kozakiewicz J, Wrzokkowa T. Treponema pallidum in lesion of early syphilis. Annals Med Sect Pol Acad Sci 1976; 21:63-4.

4. Metz J, Metz G. Elektronenmikroskopischer nachweis von Treponema pallidum hautefflorescezen der unbehandelten lues I und II. Arch Dermatol Forsch 1972;243:241-54.

5. Sykes J, Miller J, Kalan A. Treponema pallidum within cells of primary chancre from a human female. $\mathrm{Br} J$ Vener Dis 1974;50:40-4.

6. Braverman L, Yen A. Ultrastructure of the human dermal microcirculation. J Invest Dermatol 1977; 68:44-52.

7. Twomey JJ, Sharkey $O \mathrm{Jr}$, Brown JA, et al. Cellular requirements for the mitotic response in allogeneic mixed leucocyte cultures. J Immunol 1970; 104: 845-53.

8. Owczynnikow N, Delektorskij V. Treponema pallidum in nerve fibres. Br J Vener Dis 1975; 51:10-4.

9. Musher DM, Izzat NN, Mink KW, et al. In vitro phagocytosis of avirulent $T$ pallidum by rabbit macrophages. Acta Dermato Venereol 1972;52:349-52.

10. Brause B, Roberts R. Attachment of virulent Treponema pallidum to human mononuclear phagocytes. Br J Vener Dis 1978;54:218-24. 